\title{
Analysis of Intelligent Furniture Design for the Elderly in Internet of Things Era
}

\author{
Jiannan Zheng \\ College of Art \\ Yanching Institute of Technology \\ Hebei, China
}

\begin{abstract}
This paper puts forward the design principle of intelligent furniture for the elderly based on big data and intelligent technology. The present situation and demand of intelligent furniture for elderly people are analyzed.Summed up the design method of intelligent furniture for elderly people.
\end{abstract}

Keywords-Internet of things(IOT); Big data; Furniture design for the elderly

\section{INTRODUCTION}

\section{A. Social Background of the Internet of Things}

At present, IOT technology has been raised to the national strategic height with the advent of a new era of economy.The ultimate goal of the Internet of things is to achieve communication between people and objects. The most basic starting point is to serve people.Smart home is an important performance of the IOT technology and is still a lot of room for improvement and development in market.

\section{B. Social Background of Aging Population}

The total number of people aged over 60 has reached 600 million.More than 60 countries have entered the ranks of an aging society with the elderly population reaches or exceeds 10 percent of the total population. The rapid development of the aging population has attracted the attention of the United Nations and governments all over the world.According to the latest statistics released by the National Bureau of statistics, China's population aged over 60 reached 222 million, accounting for $16.1 \%$ of the total population.Aged over 65 reached 144 million, accounting for $10.47 \%$ of the total population.2025 is the peak of China's aging population,aging population is expected to reach 300 million.

\section{Market Situation of Furniture for Elderly People}

There is a growing market demand in products for elderly people in the social background of aging population.Furniture for elderly people is a major part of the elderly supplies and designers and businesses need more attention.At present, China's design of furniture for elderly people is relatively backward.Furniture used by older people is not very different from most furniture on the market and is not bringing more convenient for the elderly.

Design of furniture for elderly people is highly valued in developed countries.For example, the US Berkline functional sofa has an auxiliary function.It can be tilted and laid,can self-stretch, and the old people can stand freely and comfortably.A variety of highly automated devices for the elderly have been developed in Japan such as special utensil and shower for elderly people to eat and bathe.

\section{CHARACTERISTIC ANALYSIS OF IOT TECHNOLOGY AND FURNITURE FOR ELDERLY PEOPLE}

\section{A. Introduction to the Internet of Things}

The Internet of things is an information bearer based on the Internet and traditional telecommunication networks.It is a network that enables all common physical objects that can be independently addressed to interconnect.Through the Internet of things, the central computer can be used for centralized management and control of machines, equipment and personnel, and remote control of household equipment, automobiles, and searching places to prevent objects from being stolen.The Internet of things is usually a wireless network, and each person can connect the real object to the network through the electronic tag, and the specific location and related information can be found on the Internet of things.

\section{B. Characteristic Analysis of Intelligent Furniture for Elderly People in IOT Era}

Intelligence is the inevitable trend of the development of furniture for elderly people in IOT Era.It can create a more convenient, safe, comfortable and healthy home environment for the elderly.

The control center and output terminal of intelligent furniture should be more widely combined with daily furniture in IOT Era. Realizes the data sharing between the furniture and the equipment through the wireless connection way.

Intelligent furniture oriented user object is family. Older people live longer in the home space than the rest of the family, so older people are more closely associated with furniture.The adaptability of intelligent furniture should be paid more attention to the elderly.Design of intelligent furniture for elderly people should meet the needs of the elderly.Especially in the aspect of intelligent operation should reflect the humanistic care for the elderly. 


\section{CHARACTERISTICS AND DEMAND ANALYSIS OF THE ELDERLY}

\section{A. Physiological Characteristics}

The physical function of the elderly declines, which brings many inconveniences to the life of the elderly.Decline in physiological functions, such as diminished strength and sluggish movements.Decreased perception, such as hearing loss and visual loss.Learning abilities decline, such as slow thinking, slow reaction and poor memory.

\section{B. Psychological Characteristics}

The psychological aspect has produced the very big change after the old people quit the social stage.They worry about losing their value, eager to be valued and recognized by relatives and friends, do not want to lose the external connections.So many elderly people are looking for social activities that reflect their own value after retirement, trying to learn new things and maintaining integration with society and the surrounding environment.

\section{Health Characteristics}

The health of the elderly is also a key issue of concern.The elderly suffer from a variety of chronic diseases, such as hypertension, diabetes, myocardial infarction and other chronic diseases.So it is necessary to examine the health status of the elderly regularly.Also need to be in assisted treatment and care for the elderly In the home environment.

\section{Demand Analysis of Intelligent Furniture for the Elderly}

The following points are summed up according to the physiological and psychological characteristics of the elderly and the problems existing in the process of using furniture in the elderly.

- Security assurance.

- Convenient to contact with the outside world.

- Care of Physical health and monitoring of physiological parameters.

- Assist daily activities.

- Automation function to reduce operation.

- Danger alert function.

- The embodiment of self individuality.

\section{DESIGN PRINCIPLE OF INTELLIGENT FURNITURE FOR THE ELDERLY IN IOT ERA}

The design of intelligent furniture for the elderly should consider the following aspects according to the technical background of the Internet of things era, as well as the characteristics and needs of the elderly.

\section{A. Safety Principles}

Two factors need to be considered in the safety of intelligent furniture for the elderly, On the one hand is the safety of the dimension of furniture and shape, should according to the characteristic of old person body
function.To design suit furniture size and shape of old people to use.On the other hand is the security of the using process.Intelligent furniture for the elderly needs to interact with older people. Such furniture is unsafe for users if the user can not correctly operate.Ensure the safety of the elderly people in the use of furniture because of the elderly and is slow and not active.

\section{B. Usability Principle}

The usability design mainly involves the interaction process between the elderly and the intelligent furniture.We need to "people-oriented" throughout the design of intelligent furniture to improve the ease of use of furniture.The design should be easy to operate and understand.The interaction of furniture should accord with the physical characteristics of the elderly.Reasonable design of furniture interactive mode, operation procedure, information tips and other content to bring more convenient to the elderly.

\section{Fault tolerance Principle}

The elderly will have a misoperation because of the decline of the active power, eyesight, hearing, and memory. The design of furniture should prevent the wrong operation of old people and allowing or automatically correcting errors in the elderly.Improving the reliability and humanization of the furniture design.

\section{Emotional Principle}

The elderly desire to be loved by their relatives and friends, afraid of being out of touch with society. At the same time, most of the old people in modern society have a certain cultural base. They are more interested in learning new things and new knowledge, and hope to lead a richer and more wonderful life in their later years.Therefore, the intelligent furniture for the elderly should not only meet the physiological needs of the elderly in the function, but also need to meet the emotional needs of the elderly.In order to embody the emotional principle of intelligent furniture design,it should set up the function that publishes household life dynamic in network,personalized customizable furniture and communication between furniture and the elderly.

\section{ANALYSIS OF INTELLIGENT FURNITURE DESIGN FOR ELDERLY PEOPLE IN INTERNET OF THINGS}

The design should be based on the physiological, psychological and other needs of the elderly. The design method is summarized as follows in combination with the Internet of things, big data and other technologies.

\section{A. Intelligent Design Based on Big Data}

Today, the era of big data has been opened, it can better serve the design by using big data technologies and provide more reference and help for intelligent furniture.

1) The records and analysis of the data: Furniture should use big data technology, record and analyze living habits, physical health, furniture use status and other related data of the elderly. According to the statistical results of big data, automatically create suitable for the elderly comfortable, convenient and safe living environment. 
a) Record and analyze data of habits: The use of furniture by older people is mainly in the home environment. The intelligent furniture uses its own and home space sensors, monitors and other equipment to record the rest time, lighting intensity, activity routes, regions and other related data of older people.We can create a suitable living environment for the elderly by using data analysis results.

b) Record and analyze data of physical health: Intelligent furniture can be combined with health monitoring equipment and monitor the physiological parameters of old people automatically in the process of using furniture. The physiological parameters will be recorded and analyzed. It can remind promptly when the physiological parameters of abnormal changes.At the same time, the elderly can realize their physical and living conditions in real time through furniture or other terminal equipment by the results of the analysis of the physiological parameters.

c) Record and analyze data of use condition of furniture: The Intelligent furniture should have the function that set size, function and using time of furniture according to the user's needs. It can record the data of the furniture using status automatically. It will adjust to the furniture status that meets the user's needs automatically when users use furniture. Reduce the operation of the elderly and provide more convenient.

2) Data Sharing: The physiological parameters, furniture usage, living habits and other data which is recorded by intelligent furniture will be shared with the family and doctor through the network and wireless communication equipment. The data will be uploaded to the data platform and family will master the living conditions of the elderly expediently.

It can integrate multi-terminal data of elderly self check, community monitoring and medical examination, and integrate multiple systems of family, community, health management center and social institution.Constructing multidimensional health management platform to help old people understand their health and preventive and therapeutic measures are taken in time.As shown in "Fig.1" and "Fig. 2".

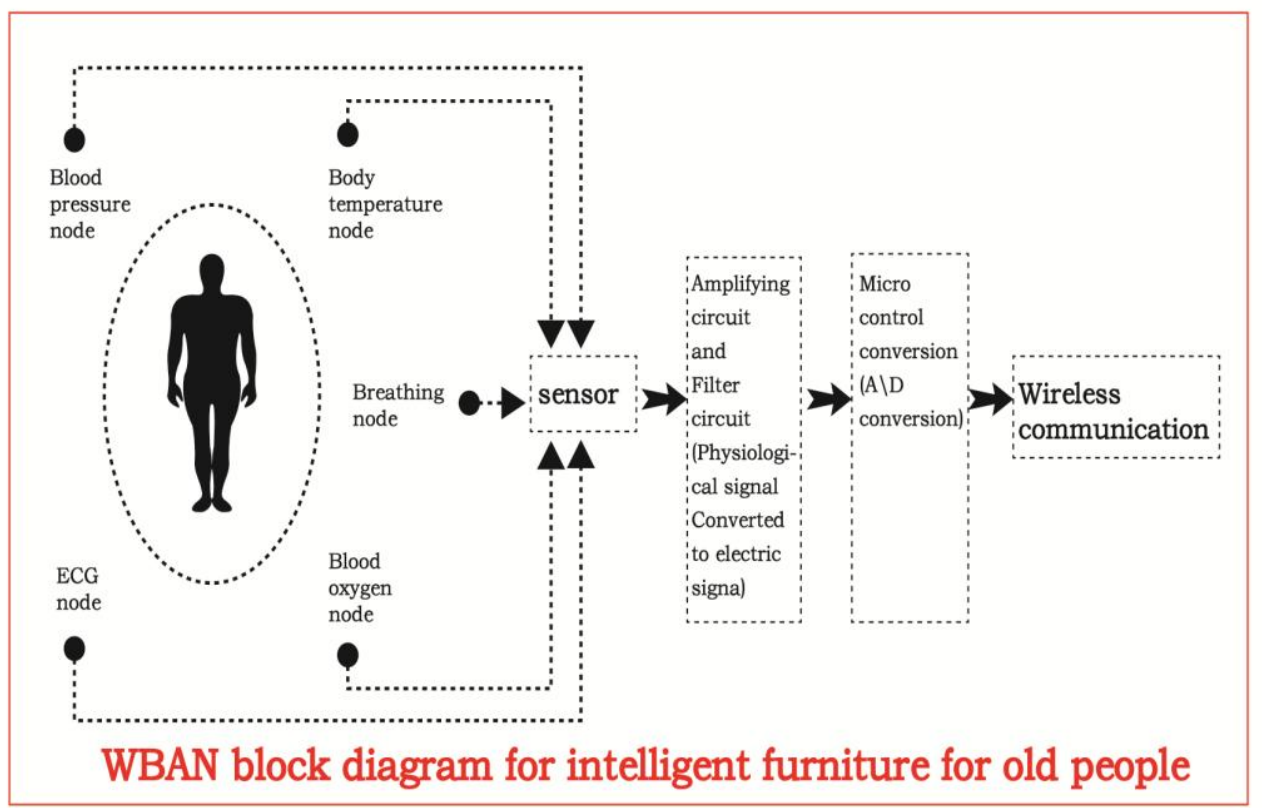

Fig. 1. Framework of data sharing for intelligent furniture. 


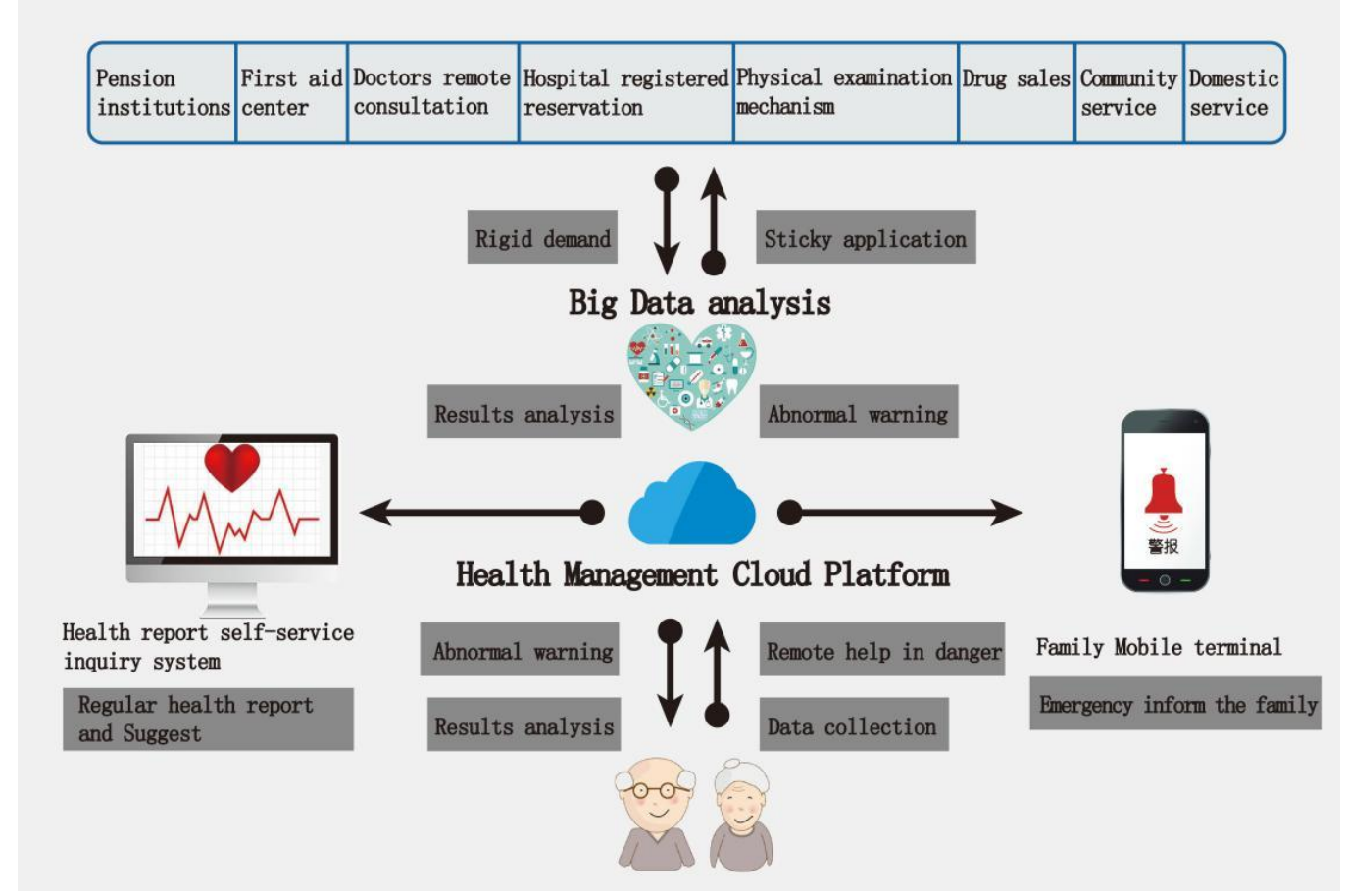

Fig. 2. Large data sharing of furniture -- Taking physiological parameters as an example.

\section{3) Abnormal Data Alarm:}

Realize the automatic alarm when the intelligent furniture and equipment to monitor the abnormal data of the elderly.Alarm information is transmitted to the family, cooperative hospitals, emergency centers and other terminal equipment to remind families, doctors to take timely measures.Minimize the risk of the elderly and bring health and safety to the elderly.

\section{B. Function for the Elderly}

Intelligent furniture in addition to have the traditional functions, but also to give more diverse and user-friendly features by using IOT, big data or other technologies.

1) Function of Health Care: The health problems of the elderly are very serious, and many elderly people need assistive devices or nursing staff. Thus, the intelligent furniture needs to have medical care function to help the elderly. Such as the function of massage, turn over and rehabilitation training can be combined with the intelligent furniture to complete the rehabilitation and care of the body.

2) Danger Alarm: The elderly may fall, faints and so on the sudden situation because of bodily function drops.It may aware of the dangerous situation at the first time and alarm timely by using pressure sensing technology and real-time monitoring equipment, etc. For example, the pressure sensing device and WIFI transmission can be combined with the mattress. When the old person leaves the bed longer than the upper limit in night, the mattress would alarm automatically for help.As shown in "Fig. 3".

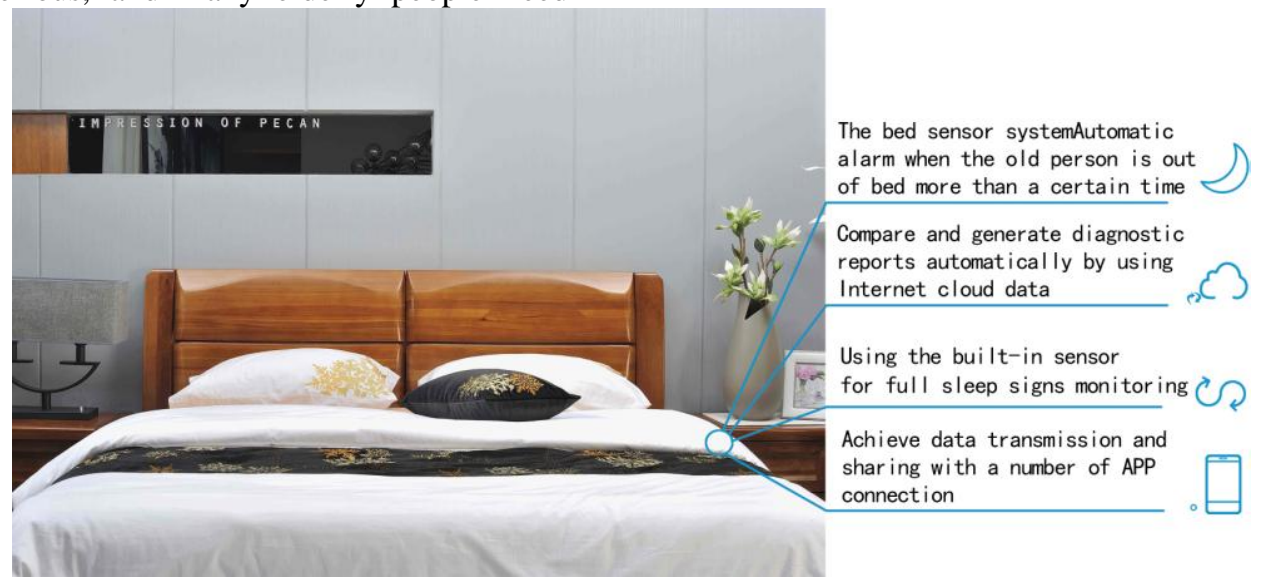

Fig. 3. Safety monitoring in night. 
3) Assisting the Daily Activities of the Elderly: On the basis of ensuring the main functions, the intelligent furniture should have additional auxiliary functions to meet the daily activities and life needs of the elderly.

According to the situation that the old person is difficult to sit down and stand up, it can set function to adjust height and Angle of seat intelligently.In the case of sitting or standing up for the elderly, adjust the furniture in time.As shown in "Fig. 4".

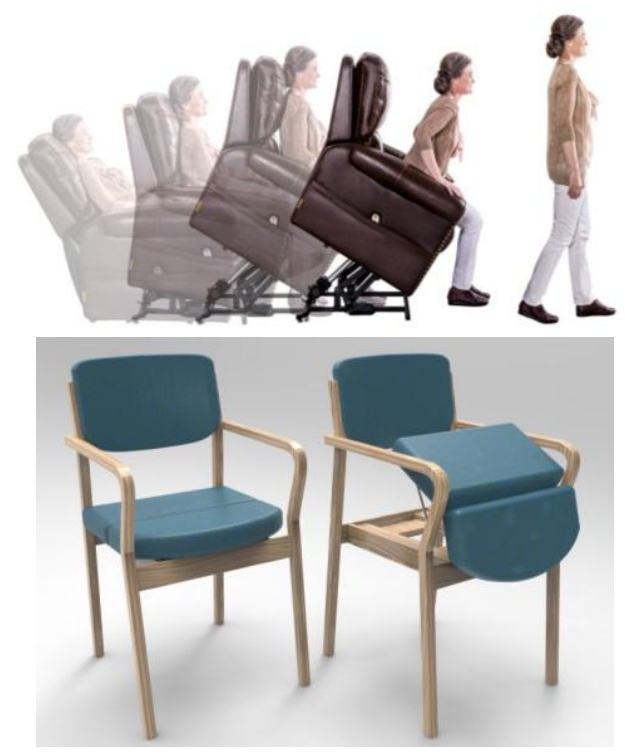

Fig. 4. The seat that helps the elderly stand up.

\section{Modeling for the Elderly}

In addition to avoiding dangerous designs such as sharp corners, the design of intelligent furniture should meet the psychological needs of the elderly.The following two aspects can be considered.

1) Style for the elderly: Intelligent furniture should be different from the conventional medical care furniture modeling, creating a comfortable home atmosphere for the elderly.At the same time, the Intelligent furniture for the elderly should be also distinguished from other intelligent furniture which has technology and modern style. To meet the aesthetic needs of the elderly, to create a culture, simple, generous home atmosphere.

2) Variability of styling: In today's society, the mentality of the elderly is relatively young, and they hope to have a variety of quality of life.According to such psychological needs, the use of intelligent technology to achieve the visual effects of furniture variability.For example, furniture combines with electronic display technology.Furniture surface color, texture, decorative patterns and other visual elements can be carried out according to individual needs.

\section{Interaction Design}

The intelligent furniture may realize each function through the interactive operation between the user and furniture. Interactive design of intelligent furniture needs to pay attention to the following aspects.

1) Information redundancy design: Redundancy design refers to the introduction of repetition or substitution of system elements to improve operational reliability to ensure that the system continues to run when the particular element fails. The output and input information of the intelligent furniture should have enough redundancy to ensure that the old people can receive the information of the furniture output accurately.At the same time, ensure that the old people input information instructions can be received by furniture. For example, the successful operation of information can appear through the screen.At the same time, the text should be prompted by flashing, shining, and even sending a successful operation, prompting tone and other information to ensure that the old people can receive the information accurately.As shown in "Fig. 5".

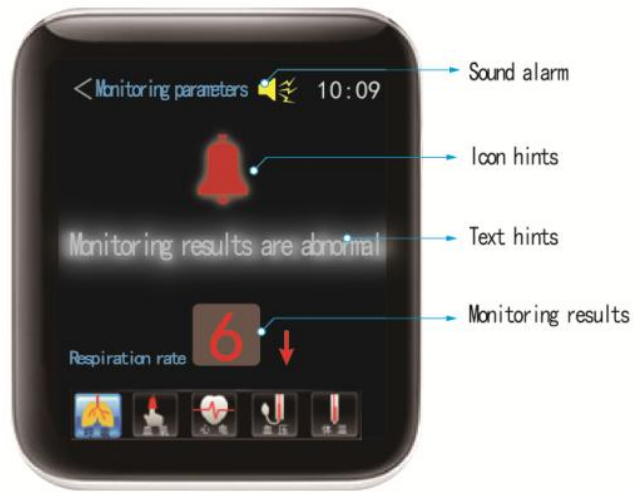

Fig. 5. Information prompt for Monitoring results of physiological parameters.

2) Multiple interaction modes: The misoperation is unavoidable because of the weak physiological function of the elderly.In order to ensure the accuracy and effectiveness of the operation, a variety of interactive methods can be used at the same time.For example,the intelligent furniture input can be executed in two ways, the action interaction and the voice interaction.As long as a way to operate successfully, it can start the massage function.

3) Slow down operation speed: According to the old people's physiological phenomena of slow movement, reaction and cognitive decline,the operation of humancomputer interaction should be slowed down.Extend the time interval between each of the two steps, slow down the speed of the visual interface, and ensure that the old person can receive the information and complete each operation accurately.

\section{E. Man-machine Size}

Ergonomic size is the basis of furniture design.Intelligent furniture should adjust and redesign the furniture size according to the special characteristics of the old man's body size and movement habits. Conventional furniture size data cannot be used. 
1) Size of furniture: The size of the furniture for the elderly should be in accordance with the size of the old man and the habit of movement. Part of the data of old people's body size is shown in "Table. I" and "Table. II". Compared with adults, the size of the hip width increases and the height generally decreases, as shown in "Fig. 6" and "Fig. 7".The old man's height is about 2 percent lower and old woman's height is about 3 percent lower.Refers to the joints thick, and the action is slow, not flexible, difficult to sit.For example, because the decline in elderly height, bend and lift is not convenient.The wardrobe is designed to be shorter than regular furniture, while raising the distance between the bottom and the floor of the wardrobe to prevent the elderly from stooping to take things.As shown in "Fig. 8".
TABLE I. Standing Posture And Hip Wide Size of ChinA's ELDERLY

\begin{tabular}{lrrr}
\hline Test items & Percentile & Height $(\mathrm{mm})$ & $\begin{array}{r}\text { Hip circumference } \\
(\mathrm{mm})\end{array}$ \\
\hline \multirow{6}{*}{$60-70$ ages } & P1 & 1507 & 752 \\
man & P5 & 1549 & 803 \\
& P10 & 1572 & 830 \\
& P50 & 1651 & 926 \\
& P90 & 1730 & 1022 \\
& P95 & 1753 & 1049 \\
\hline & P99 & 1795 & 1100 \\
\hline \multirow{4}{*}{$60-70$ ages } & & & 745 \\
woman & P1 & 1404 & 800 \\
& P5 & 1443 & 830 \\
& P10 & 1464 & 933 \\
& P50 & 1538 & 1036 \\
& P90 & 1612 & 1066 \\
& P95 & 1633 & 1122 \\
\hline
\end{tabular}

TABLE II. Sitting Posture Size OF ChinA's Elderly

\begin{tabular}{|c|c|c|c|c|c|c|c|c|c|c|c|}
\hline \begin{tabular}{|l} 
Test \\
items
\end{tabular} & $\begin{array}{l}\text { Perc- } \\
\text { en- } \\
\text { tile }\end{array}$ & $\begin{array}{l}\text { Sitting } \\
\text { height(mm) }\end{array}$ & $\begin{array}{l}\text { Sitting } \\
\text { height of } \\
\text { shoulder } \\
\text { and neck } \\
\text { (min) }\end{array}$ & $\begin{array}{l}\text { sitting } \\
\text { shoulder } \\
\text { heigh(min) }\end{array}$ & $\begin{array}{l}\text { Sitting } \\
\text { Elbow } \\
\text { height } \\
\text { (min) }\end{array}$ & $\begin{array}{l}\text { Sitting } \\
\text { knee } \\
\text { height } \\
(\mathrm{mm})\end{array}$ & $\begin{array}{l}\text { A lourer leg } \\
\text { plus the zoo } \\
\text { height(min) }\end{array}$ & $\begin{array}{l}\text { body } \\
\text { depth, } \\
\text { sitting } \\
\text { (min) }\end{array}$ & $\begin{array}{l}\text { The distance } \\
\text { from the hip } \\
\text { to the knee } \\
(\mathrm{mm})\end{array}$ & $\begin{array}{l}\text { Sitting } \\
\text { thickness of } \\
\text { thigh } \\
(\mathrm{min})\end{array}$ & $\begin{array}{l}\text { sittinghi } \\
\text { p breadth } \\
(\mathrm{mm})\end{array}$ \\
\hline \multirow{7}{*}{$\begin{array}{l}60-70 \\
\text { ages } \\
\text { man }\end{array}$} & P1 & 816 & 585 & 526 & 209 & 431 & 361 & 398 & 487 & 99 & 274 \\
\hline & P5 & 840 & 602 & 545 & 223 & 446 & 375 & 412 & 504 & 112 & 294 \\
\hline & P10 & 853 & 612 & 555 & 230 & 455 & 381 & 420 & 514 & 117 & 304 \\
\hline & P50 & 893 & 646 & 588 & 259 & 485 & 406 & 450 & 545 & 138 & 340 \\
\hline & P90 & 934 & 682 & 612 & 287 & 516 & 433 & 479 & $5 \pi$ & 157 & 374 \\
\hline & P95 & 946 & 692 & 633 & 294 & 525 & 442 & 488 & 588 & 163 & 384 \\
\hline & P99 & 969 & 711 & 652 & 309 & 543 & 458 & 505 & 607 & 174 & 402 \\
\hline \multirow{7}{*}{$\begin{array}{l}60-70 \\
\text { ages } \\
\text { woman }\end{array}$} & P1 & 764 & 545 & 488 & 195 & 397 & 321 & 376 & 466 & 100 & 276 \\
\hline & P5 & 788 & 563 & 504 & 209 & 412 & 333 & 390 & 481 & 110 & 301 \\
\hline & P10 & 798 & 572 & 512 & 217 & 420 & 351 & 397 & 489 & 116 & 314 \\
\hline & P50 & 838 & 604 & 545 & 246 & 449 & 374 & 424 & 518 & 135 & 357 \\
\hline & P90 & 876 & 637 & 575 & 272 & 477 & 392 & 453 & 551 & 155 & 398 \\
\hline & P95 & 887 & 647 & 585 & 280 & 485 & 399 & 462 & 561 & 161 & 407 \\
\hline & P99 & 906 & 665 & 600 & 295 & 500 & 411 & 478 & 578 & 172 & 430 \\
\hline
\end{tabular}

Height contrast between adult men and older men

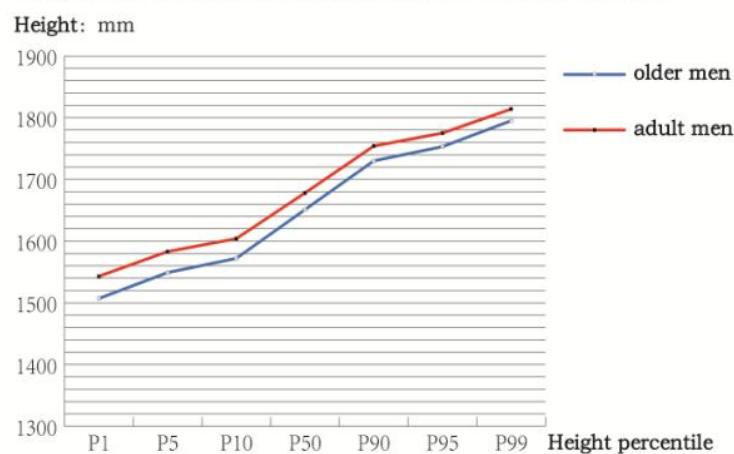

Fig. 6. Height comparison between adult and elderly men.
Height contrast between adult women and older women

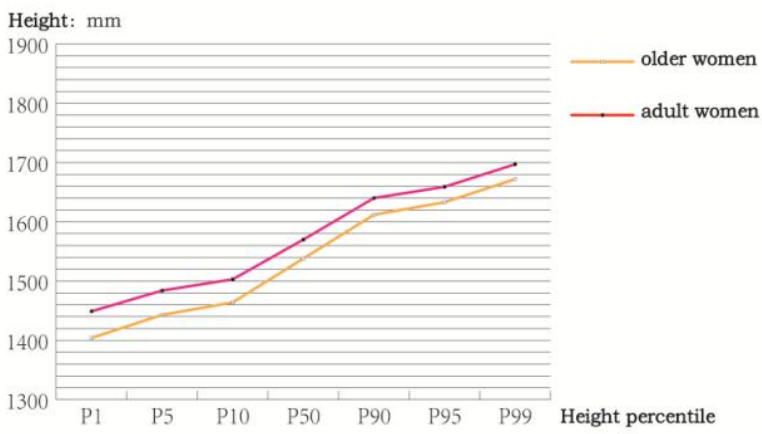

Fig. 7. Height comparison between adult and elderly women. 


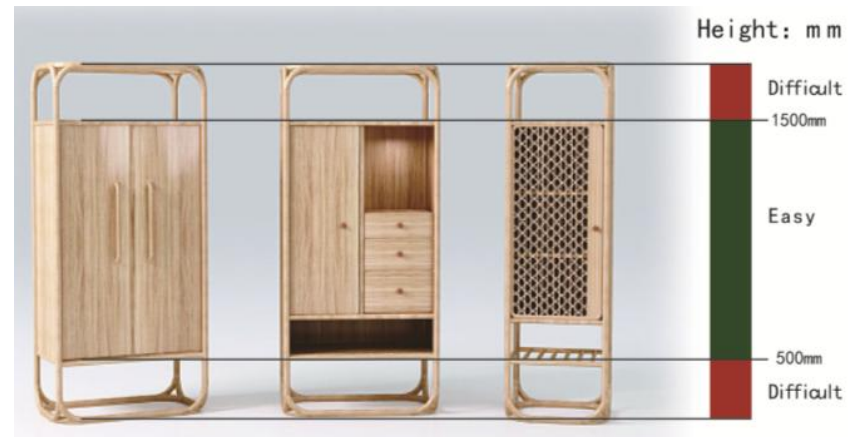

Fig. 8. Height design of Wardrobe for the elderly.

2) Variability of furniture height: According to the characteristics of the elderly such as activity inconvenience, furniture can be combined with the technical advantages.According to the needs of the elderly in different state of furniture, adjust the height, width, tilt angle and other dimensions of the furniture automatically. Ensure the elderly more convenient to use furniture.For example, the cabinet is too high, not convenient for the elderly to take things. According to the height of the old people, the automatic lifting cabinet can be set up to facilitate the old people to take things easily. As shown in "Fig. 9".

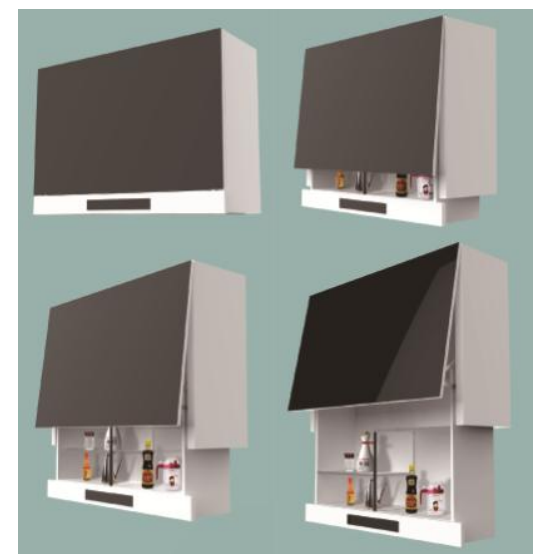

Fig. 9. The height of the cabinet can be adjusted automatically.

\section{CONCLUSION}

Intelligent design should be human centered in the era of Internet of things.It is not meaningful and valuable to consider only technological updates and progress out of the human needs.Therefore, the design of the intelligent furniture should be based on the physiological and psychological characteristics of the elderly and meet the needs of the elderly.Make full use of the Internet of things, big data technology, design more user-friendly intelligent furniture.Create a healthy, comfortable, safe and convenient home environment for the elderly.

\section{REFERENCES}

[1] Gan.Long, "Analysis and Practice of Humanized Design of Furniture For the Elderly", Decoration, 2016.

[2] Wu.Peng," Research on physiological characteristics of the elderly and product design ", Art and design, 2013.
[3] Shu.Wenqiong, "Five giants contend for intelligent furniture",Communication world, 2010.

[4] Xue.Yaping, "Research on the design of daily necessities for the elderly under the background of population aging",Art and design, 2014.

[5] Zhang.Wei, "Research on intelligent home of Internet of things under big data background", Technological, 2016. 